\title{
Making Mental Health a Priority on College Campuses: Implementing Large Scale Screening and Follow-up in a High Enrollment Gateway Course
}

Flora-Jean M. Forbes

Missouri State University, Flora314@live.missouristate.edu

As with any intellectual project, the content and views expressed in this thesis may be considered objectionable by some readers. However, this student-scholar's work has been judged to have academic value by the student's thesis committee members trained in the discipline. The content and views expressed in this thesis are those of the student-scholar and are not endorsed by Missouri State University, its Graduate College, or its employees.

Follow this and additional works at: https://bearworks.missouristate.edu/theses

Part of the Clinical Psychology Commons

\section{Recommended Citation}

Forbes, Flora-Jean M., "Making Mental Health a Priority on College Campuses: Implementing Large Scale Screening and Follow-up in a High Enrollment Gateway Course" (2018). MSU Graduate Theses. 3259.

https://bearworks.missouristate.edu/theses/3259

This article or document was made available through BearWorks, the institutional repository of Missouri State University. The work contained in it may be protected by copyright and require permission of the copyright holder for reuse or redistribution.

For more information, please contact BearWorks@library.missouristate.edu. 


\title{
MAKING MENTAL HEALTH A PRIORITY ON COLLEGE CAMPUSES: \\ IMPLEMENTING LARGE SCALE SCREENING AND FOLLOW-UP IN A HIGH ENROLLMENT GATEWAY COURSE
}

\author{
A Master's Thesis \\ Presented to \\ The Graduate College of \\ Missouri State University \\ In Partial Fulfillment \\ Of the Requirements for the Degree \\ Master of Science, Psychology - Clinical Track
}

By

Flora-Jean Marie Forbes

May 2018 
MAKING MENTAL HEALTH A PRIORITY ON COLLEGE CAMPUSES:

IMPLEMENTING LARGE SCALE SCREENING AND FOLLOW-UP IN A HIGH

ENROLLMENT GATEWAY COURSE

Psychology

Missouri State University, May 2018

Master of Science

Flora-Jean Marie Forbes

\begin{abstract}
Objectives: A universal mental health screening program for undergraduate students was implemented using graduate student clinicians and online interviewing tools.

Participants: Participants included 455 undergraduate students at a large Midwestern University enrolled in introductory psychology. Methods: Participants in the experimental group first completed an in-class self-report mental health screening questionnaire. Based on subscale elevations, students scoring in an "at risk" range on any subscale were invited to participate in individual online follow-up interviews to assess risk level and provide referral information. Results: Results demonstrated that a majority of undergraduate students scored in an at-risk range on at least one subscale on a mental health screening questionnaire, and follow-up interviews were successfully conducted for $40 \%$ of students with elevations. Perceptions of campus mental health priorities improved over a three-month period from the time of the initial screening. Conclusions: Universal campus mental health screening was successfully implemented using graduate student clinicians resulting in a large number of referrals for mental health treatment and improved perceptions of mental health treatment on campus.
\end{abstract}

KEYWORDS: mental health, college counseling center, screening, graduate training, online screening

This abstract is approved as to form and content

Brooke Whisenhunt, $\mathrm{PhD}$

Chairperson, Advisory Committee

Missouri State University 


\title{
MAKING MENTAL HEALTH A PRIORITY ON COLLEGE CAMPUSES: \\ IMPLEMENTING LARGE SCALE SCREENING AND FOLLOW-UP IN A HIGH ENROLLMENT GATEWAY COURSE
}

\author{
By \\ Flora-Jean Marie Forbes \\ A Master's Thesis \\ Submitted to the Graduate College \\ Of Missouri State University \\ In Partial Fulfillment of the Requirements \\ For the Degree of Master of Science, Psychology - Clinical Track
}

May 2018

Approved:

Brooke Whisenhunt, $\mathrm{PhD}$

Danae Hudson, $\mathrm{PhD}$

Paul Deal, PhD

Julie Masterson, PhD: Dean, Graduate College

In the interest of academic freedom and the principle of free speech, approval of this thesis indicates the format is acceptable and meets the academic criteria for the discipline as determined by the faculty that constitute the thesis committee. The content and views expressed in this thesis are those of the studentscholar and are not endorsed by Missouri State University, its Graduate College, or its employees. 


\section{ACKNOWLEDGEMENTS}

I would like to begin by thanking my thesis committee for providing unwavering support while taking on this incredibly involved and time consuming thesis project. I would like to extend extra thanks to my chairperson, Dr. Whisenhunt for the time she put into helping me make this project a reality and for the sacrifices (including the loss of a stress-free Halloween) she made for this to be successful. Additionally, I am extremely grateful to the clinical faculty who volunteered to be on-call during the follow-up phase of my thesis in the case of any crisis situations.

I would also like to thank my cohort members (Robiann Broomfield, Chiara Citterio, David Herr, Becca Johnson, and Heather Lepper) who volunteered to serve as graduate clinicians and conducted the follow-up phase of this project. I extend special thanks to Chiara Citterio for her constant support and hard work over the last year as well as for serving as a liaison to the Counseling Center to try and make the ability to refer students as easy as possible.

Finally, I would like to thank the members of the Eating Disorders and Body Image Lab (Natalie Carlson, Amy Jordan, Dallas Robinson, and Heather Stephens-Cantu) for helping to keep me positive, for providing insight and feedback throughout the creative process, and without whom this thesis project would not have been possible. 


\section{TABLE OF CONTENTS}

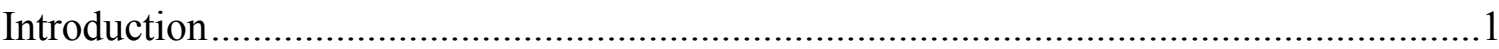

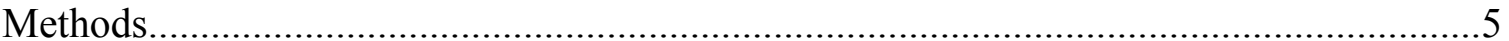

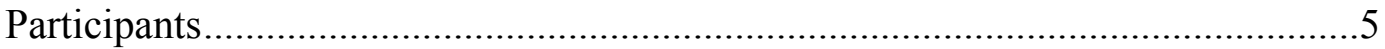

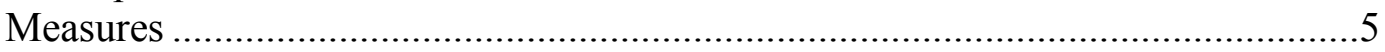

Counseling Center Assessment of Psychological Symptoms-62 ..................5

Perceptions of Mental Health Care on Campus Questionnaire (PMHCCQ)..6

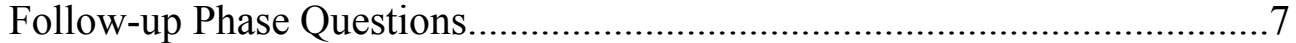

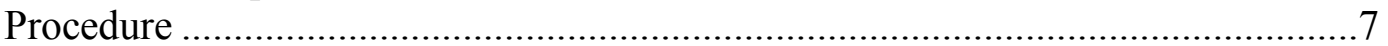

Screening Phase ................................................................................. 7

Follow-up Phase .............................................................................. 8

Three Month Follow-Up ................................................................... 10

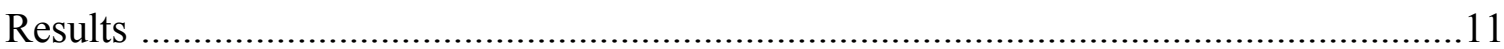

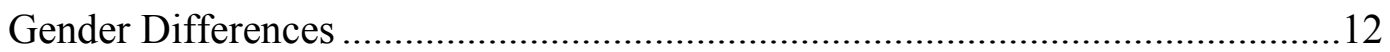

Perceptions of Mental Health Care on Campus .....................................................15

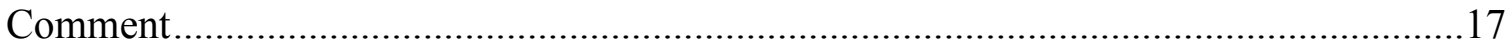

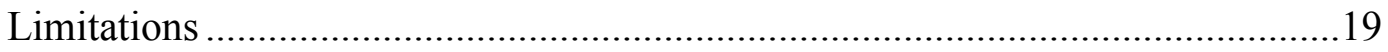

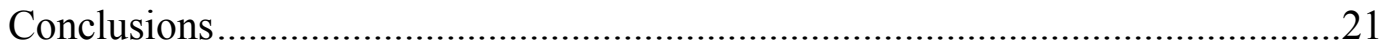

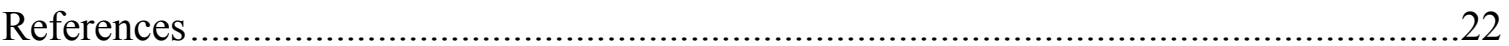

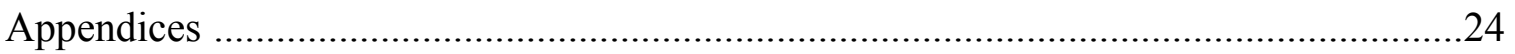

Appendix A. Perceptions of Mental Health Care on Campus Questionnaire........24

Appendix B. Human Subjects IRB Approval ...................................................25

Appendix C. Follow-Up Phase Risk Level Criteria...........................................26 


\section{LIST OF TABLES}

Table 1. Percentages and Numbers of Participants Elevated on Each Subscale. ..............12

Table 2. Gender Differences in Subscale Elevations on modified CCAPS-62 ................13 


\section{LIST OF FIGURES}

Figure 1. Mean Scores on Individuals Items of the Perceptions of Mental Health Care on

Campus Questionnaire with Error Bars Displaying the Standard Error. .........................16 


\section{INTRODUCTION}

Mental health on college campuses has increasingly become a topic of national interest. Data provided by university Counseling Center directors indicated that, of the college students who seek out services, $51 \%$ are affected by anxiety, $41 \%$ are affected by depression, and $34 \%$ struggle with relationship issues. ${ }^{1}$ In addition, among the students who received campus counseling services, $24.5 \%$ reported taking psychotropic medications. ${ }^{2}$ The majority of Counseling Center directors (70\%) reported the number of students with severe psychological problems being much higher than the previous year, ${ }^{2}$ and $19 \%$ of directors described the availability of psychiatric services as inadequate due to high demand. ${ }^{2}$ Even more concerning is the fact that the majority of students are not receiving mental health services despite high levels of distress. For example, $80 \%$ of students who die by suicide have never used their campus counseling center. ${ }^{3}$

The Healthy Minds Study spanning from 2007 to 2013 examined mental health needs and service utilization on college campuses. ${ }^{3}$ This study revealed that across 72 colleges $(\mathrm{n}=42,210), 18.2 \%$ of students screened positive for depression, $10.1 \%$ for anxiety, $7.8 \%$ had serious thoughts of suicide, and $16.5 \%$ reported non-suicidal selfinjury in the previous year. ${ }^{3}$ Of the students surveyed, $34.4 \%$ had at least one of the listed mental health problems. ${ }^{3}$ However, among students who had identifiable mental health concerns, less than half of them (39.4\%) reported receiving treatment. ${ }^{3}$ These numbers suggest that although students are experiencing mental health problems, a majority of them are not seeking or receiving help. Eisenberg et al. found similar results with $32 \%$ of college students endorsing symptoms compatible with a mental health 
diagnosis while $64 \%$ of those who were symptomatic did not report receiving mental health treatment. ${ }^{4}$

Despite the fact that college campus counseling centers have been found to be extremely helpful in assisting students, the students who receive those services are typically self-referred. ${ }^{5}$ Many college campuses provide some mental health screening and have even used online forums and social media to reach more students, but again, participants in such screening events are typically self-referred. ${ }^{6}$ One way to increase awareness of the potential need for mental health services among students is to implement universal screening programs where all students are provided with an opportunity to engage in mental health screening and receive appropriate feedback. Dowdy et al. argue that universal screening for complete mental health should be brought to the front of the delivery system, in order to emphasize prevention and early intervention. ${ }^{7}$ The goal is to shift the approach to mental health from reactionary to preventive. However, while universal screening could be an excellent way to reach the whole college population rather than the small percent of students who actively seek help, there are various obstacles related to implementation. Specifically, universal screening requires significant resources in terms of time, facilities, and personnel.

Two potential ways to alleviate the high-resource demand of universal screening include 1) utilizing graduate students enrolled in mental health training programs to assist in implementing universal screening, and 2) taking advantage of technology to conduct confidential, individual screening and risk-assessment. As stated by Furr, training graduate students and allowing them the opportunity to gain practical experience is a cost-effective way to increase the possibility that university counseling centers can offer 
services without experiencing further burden on limited resources. ${ }^{8}$ Furr discusses the benefits of having counseling and psychology students intern at university counseling centers in order to gain first-hand experience, while also allowing the center to serve more clients. ${ }^{8}$ In addition, Rodriguez et al. indicated that experiential learning, more specifically experiencing emotionally-charged encounters, is incredibly important for clinical psychology students. ${ }^{9}$ Therefore, involving graduate students in this type of clinical activity appears to be one possible solution to implementing universal screening while reducing the need for further resources at universities.

The use of online tools to conduct confidential individual mental health screening and risk-assessment has the potential to reduce the resource demands for institutions (e.g., finding large numbers of private rooms for individual meetings) and increase the likelihood that students will participate by providing flexible appointment times for virtual meetings that can be conducted anywhere (e.g., in a student's own dorm room or apartment). The main concerns related to the provision of any online mental health services are generally related to crisis management and confidentiality. ${ }^{10,11}$ In terms of confidentiality it is important to utilize software and programs that have been specifically developed in order to protect confidentiality and are HIPAA compliant. With regards to concerns about crisis management, evidence suggests that crisis situations can be effectively resolved using online formats when trained clinicians ask detailed questions and have resources readily available to support their clients. ${ }^{12}$ Recent evaluations of online therapy suggest that people may get just as much benefit from participating in online therapy as they get from seeing a therapist face-to-face, ${ }^{12}$ suggesting that online screening tools may also be effective. 
The high rate of mental health concerns among students combined with the relatively low rate of self-referrals to campus counseling centers suggests the need for universal screening programs. The current study sought to pilot a universal screening program utilizing graduate student clinicians and online individual follow-up interviews for at-risk students. It was hypothesized that approximately $30 \%$ of students would score in an "at risk" range on at least one subscale of a mental health screening tool, consistent with prior research suggesting levels of students suffering from symptoms consistent with a mental health diagnosis. ${ }^{3,4}$ Additionally, it was hypothesized that individuals who participate in a mental health screening will have greater perceptions of mental health on their campus than individuals who do not participate. 


\section{METHODS}

\section{Participants}

A total of 455 participants $\left(M_{\text {Age }}=19.04\right.$ years, $\left.S D_{\text {Age }}=1.91\right)$ were included in the study. In terms of gender identification, $58.8 \%(n=267)$ self-identified as "female", $40.7 \%(n=185)$ as "male", and less than $1 \%(n=2)$ as "gender non-conforming." A total of $86.9 \%(n=392)$ participants self-identified as White, $5.5 \%(n=25)$ as Other, and 4.7\% $(n=21)$ as Black. Fewer than 10 students in the study identified as Korean, "other Asian”, Chinese, Filipino, Asian Indian, or American Indian or Alaskan Native. Participants were enrolled in two sections of Introductory Psychology at a large Midwestern University. One course section was assigned to be the experimental group ( $n$ $=247)$ and the other course section was assigned to be the control group $(n=208)$. There were no significant differences in terms of demographic variables between participants in the experimental class and those in the control class. Both courses were taught by instructors who were licensed clinical psychologists and used a shared syllabus with identical course structures and assignments/grading. Participants received credit toward a course research requirement for their participation in the study.

\section{Measures}

\section{Counseling Center Assessment of Psychological Symptoms-62. The}

Counseling Center Assessment of Psychological Symptoms-62 (CCAPS-62) was utilized as the main screening tool to assess potential areas of mental health concern. The CCAPS-62 is a screening tool that was developed specifically for a college student population in order to provide a valid and reliable measure that could assess a multitude 
of symptom areas at once in order to provide a comprehensive assessment. ${ }^{13}$ Each of the CCAPS-62 subscales (depression, generalized anxiety, social anxiety, academic distress, eating concerns, family distress, hostility, substance use) was more highly correlated with a pre-existing measure of the same construct than the other constructs, ${ }^{13}$ supporting the utility of this screening tool as a multidimensional method to assess common problems in college students.

Due to the nature of a large group screening, 4 critical items identified by the creators of the CCAPS-62 were removed from the initial screening. These critical items include the questions "I lose touch with reality", "I have thoughts of ending my life", "I am afraid I may lose control and act violently" and "I have thoughts of hurting others". Affirmative answers to these items would require immediate follow-up which was problematic in a large group format. After extensive consultation with staff and faculty representing university counsel, risk management, institutional research, and administration, the primary investigator determined the following course of action to be the most appropriate one. These items were removed from the initial screening and replaced with a single item that stated "I am in significant distress and would like to speak to someone today". Students who endorsed this item were instructed to go to a room in the same building where they would be met by a mental health professional. However, no participants who endorsed this item $(n=5)$ arrived at the room. Instead, each individual was contacted vie email and/or phone to determine the immediacy of their needs and was referred to the counseling center if necessary.

Perception of Mental Health Care on Campus Questionnaire (PMHCCQ). The PMHCCQ consists of 6 questions that were developed specifically for the current 
study to evaluate student perceptions of mental health care on campus. For example, students were asked to rate the following items: "I believe that my campus cares about student mental health" and "I feel comfortable talking about issues of mental health on campus". Each question was answered using a 7-point Likert type scale where $1=$ strong disagree and $7=$ strongly agree. See Appendix A for the full questionnaire. Students completed the PMHCCQ during the initial screening phase and 3 months after the initial screening.

Follow-up Phase Questions. For each subscale of the CCAPS-62, semistructured follow-up interview questions were developed. The interview questions were developed to assist the graduate student clinicians in making informed decisions about risk level and appropriate referrals.

\section{Procedure}

Graduate Student Training. Second year students $(n=6)$ in the clinical psychology Master's program at our large Midwestern university served as graduate student clinicians in the study. Each graduate clinician attended a 3-hour training workshop. Training consisted of teaching graduate clinicians how to use the technology (e.g., online calendar, texting application, and Skype for Business), familiarization with the screening tools, and practice making risk assessments. In addition, the graduate student clinicians engaged in "mock" follow-up interviews to practice administering each set of follow-up questions.

Screening Phase. Before beginning the screening phase of this study, approval was received from the Institutional Review Board (See Appendix B). Participants in the 
control group completed a consent form, demographics questionnaire, and the PMHCCQ. Participants in the experimental group were first provided with a printed informed consent form and a verbal description of the study during the last 25 minutes of a regularly scheduled Introductory Psychology course. After completing the informed consent, participants completed a packet containing demographic questions, the modified CCAPS-62, and the PMHCCQ. The paper packet students received had two columns on each page. The study questionnaires were in the left column and the right column included multiple choice review questions pertaining to the content of their psychology course. Students who chose not to participate in the study were asked to complete the review questions so that no one could identify which individuals were participating in the study.

Follow-up Phase. After the screening phase, any participant who scored in the "high distress" range on any subscale score on any of the 8 areas of concern (depression, generalized anxiety, social anxiety, academic distress, eating concerns, family distress, hostility, substance/alcohol use) was contacted via text message to participate in the follow-up phase of the study. Graduate student clinicians utilized an online calendar and texted the link to each participant so that they could sign up for a convenient time. If a participant did not respond to the initial text, the researcher sent up to two additional text messages, and then attempted to reach the participant by phone. If the participant never responded to any attempt to contact, he/she was considered to be withdrawn from the study.

A total of 63 participants completed a follow-up interview. Participants either engaged in a follow-up interview through Skype for Business $(n=42)$, phone-call $(n=$ 
$14)$ in case of technical difficulties, or face-to-face $(n=7)$ if they did not have the technological means to participate online. Participants were asked the follow-up interview questions for each elevated subscale on the CCAPS-62. In addition, each participant was screened for suicidal ideation, and self-harm urges and/or behavior. Students who elevated on the hostility scale were also screened for homicidal ideation. If a participant was considered to have any level of elevated risk of harm to self or others that was not deemed "imminent," then the participant was to be referred for immediate follow-up at the campus Counseling Center. Participants who were not at risk of harm to self or others but who expressed other mental health distress (e.g., anxiety, depression) were provided with referral information about campus and community treatment resources. If the student indicated they were interested in visiting the counseling center, they were provided with a "release form" that allowed the research team to provide the counseling center with the follow-up packet and screening data. Although there were no students considered to be at imminent risk during the study, graduate student clinicians were trained in the following process if they were to interview a student deemed to be at imminent risk. First, the graduate student clinicians were instructed to contact the faculty member on call (faculty who were licensed clinical psychologists were "on call" at all times when follow-up interviews were conducted) and consult about the situation, while also being prepared to call the police or campus security depending on the location of the student. After making the decision that the student was at imminent risk, the graduate student clinician would work with the student to identify someone who could walk them to the counseling center or the hospital depending on the time of day. Graduate student 
clinicians were instructed not to end the Skype call until help had arrived and the student was not alone anymore.

Three Month Follow-Up. Three months from the initial in-class screening, a follow-up link to the PMHCCQ was texted to all of the participants in both the control and experimental groups. This final assessment included additional questions about whether or not the participants had considered receiving mental health treatment or pursued mental health treatment in the last 3 months. If participants responded in the affirmative, they were asked information about the number of sessions and their level of satisfaction with their mental health care. 


\section{RESULTS}

A total of 247 participants in the experimental class engaged in the large class screening. Among those students, a total of $64 \%(n=158)$ obtained an elevated score on one or more subscales of the CCAPS-62. See Table 1 for the percentages and numbers of participants who were elevated on each individual subscale. Two critical items from the depression subscale and 2 critical items from the hostility subscale were removed from the large class screening because of an inability to provide immediate individual feedback. Those items were replaced by a question allowing students to indicate if they were in distress and needed to speak with someone immediately. Although the cut scores used to determine subscale elevation were adjusted based on the revised number of total items on those two scales, it is likely that the current data represents least a slight overestimate of students who scored in an "at risk" range on the depression and hostility scales. A total of $21.6 \%(n=53)$ individuals elevated on only one subscale, $15.5 \%(n=$ 38) elevated on 2 subscales, $8.2 \%(n=20)$ elevated on 3 subscales, $6.1 \%(n=15)$ elevated on 4 subscales, $6.1 \%(n=15)$ elevated on 5 subscales, $4.5 \%(n=11)$ elevated on 6 subscales, and $2 \%(n=5)$ elevated on 7 subscales. 
Table 1. Percentages and numbers of participants elevated on each subscale

\begin{tabular}{lcc}
\hline Subscale & Participants Elevated (\%) & Participants Elevated (N) \\
\hline Depression & 23.6 & 58 \\
Generalized Anxiety & 23.9 & 59 \\
Academic Distress & 22.7 & 56 \\
Social Anxiety & 21.9 & 54 \\
Eating Concerns & 11.4 & 28 \\
Family Distress & 13.8 & 34 \\
Hostility & 24.7 & 61 \\
Substance Use & 31.2 & 77 \\
\hline
\end{tabular}

\section{Gender Differences}

In order to identify any gender differences in subscale elevations, a chi-square test was conducted for each subscale. A total of 141 females, 104 males, and one gender nonconforming individual participated in the large class screening. There was a significant gender difference on the generalized anxiety subscale, $\chi^{2}(2, N=246)=7.199, p=0.03$ social anxiety subscale, $\chi^{2}(2, N=246)=10.612, p=0.005$, eating subscale, $\chi^{2}(2, N=$ $244)=12.663, p=0.002$ with females elevating more frequently than males. There was also a significant gender difference for the substance use subscale, $\chi^{2}(2, N=246)=$ $6.262, p=0.04$ with males elevating more frequently than females. See Table 2 for all chi square statistics including non-significant findings. 
Table 2. Gender Differences in Subscale Elevations on Modified CCAPS-62

\begin{tabular}{|c|c|c|c|c|c|c|}
\hline Subscale & $\begin{array}{c}\text { Elevated } \\
(n)\end{array}$ & $\begin{array}{c}\text { Did not } \\
\text { Elevate }(n)\end{array}$ & $\begin{array}{c}\text { Total } \\
(n)\end{array}$ & $\overline{d f}$ & $X^{2}$ & $\bar{p}$ \\
\hline \multicolumn{7}{|l|}{ Depression } \\
\hline Male & 19 & 84 & 103 & 2 & 5.62 & 0.06 \\
\hline Female & 38 & 103 & 141 & & & \\
\hline Gender Non-Conforming & 1 & 0 & 1 & & & \\
\hline \multicolumn{7}{|l|}{ Generalized Anxiety } \\
\hline Male & 18 & 86 & 104 & 2 & 7.20 & 0.03 \\
\hline Female & 40 & 101 & 141 & & & \\
\hline Gender Non-Conforming & 1 & 0 & 1 & & & \\
\hline \multicolumn{7}{|l|}{ Academic Distress } \\
\hline Male & 25 & 79 & 104 & 2 & 0.44 & 0.80 \\
\hline Female & 31 & 110 & 141 & & & \\
\hline Gender Non-Conforming & 0 & 1 & 1 & & & \\
\hline \multicolumn{7}{|l|}{ Social Anxiety } \\
\hline Male & 14 & 90 & 104 & 2 & 10.61 & 0.005 \\
\hline Female & 39 & 102 & 141 & & & \\
\hline Gender Non-Conforming & 1 & 0 & 1 & & & \\
\hline \multicolumn{7}{|l|}{ Eating Concerns } \\
\hline Male & 6 & 97 & 103 & 2 & 12.66 & 0.002 \\
\hline Female & 21 & 119 & 140 & & & \\
\hline Gender Non-Conforming & 1 & 0 & 1 & & & \\
\hline
\end{tabular}


Table 2 continued. Gender Differences in Subscale Elevations on Modified CCAPS-62 \begin{tabular}{lllllll}
\hline Subscale & Elevated & Did not & Total $(n)$ & $d f$ & $X^{2}$ & $p$
\end{tabular}

(n) Elevate $(n)$

Family Distress

Male

14

90

1042

0.19

0.91

Female

20

121

141

Gender Non-Conforming

0

1

1

Hostility

Male

26

78

$\begin{array}{lll}104 & 2 & 3.07\end{array}$

0.22

Female

34

107

141

Gender Non-Conforming

1

0

1

Substance Use

Male

39

65

$104 \quad 2$

6.26

0.04

Female

36

105

141

Gender Non-Conforming

1

0

1

Overall

Male 68

36

104

2

0.80

0.67

Female

88

53

141

Gender Non-Conforming

1

0

1

Of the 158 individuals who elevated on one or more scales, $39.9 \%(n=63)$ participated in the follow-up interview, 21.5\% $(n=34)$ declined to participate, $27.8 \%(n$ 
$=44)$ never replied to the invitation to participate, $8.2 \%(n=13)$ signed up to participate but did not attend the follow-up and then never replied, and 2.5\% $(n=4)$ expressed initial interest but never signed up to participate.

During the follow-up phase, risk levels were assigned to each participant (see Appendix C for risk level criteria). Of those who completed a follow-up interview, 25.4\% $(n=16)$ were considered to be in minimal distress, $41.3 \%(n=26)$ were considered to be in low distress, $23.8 \%(n=15)$ were considered in moderate distress, and $9.5 \%(n=6)$ were considered in high distress. Any participant placed at a level of moderate distress or higher was referred to the campus counseling center. When a student was considered to be in high distress, they were recommended to seek immediate help from the counseling center.

\section{Perceptions of Mental Health Care on Campus}

The PMHCCQ was completed the day of the initial screening and 3 months after the initial screening. A series of 2 (experimental group vs control group) x 2 (time 1 vs time 2) mixed design ANOVAs were used to analyze the average score on each item of the PMHCCQ for participants. There were no significant differences on any items based on group assignment (experimental group vs control group). However, there were within group differences found on several items. There was a main effect for time on item 2 $[F(1,134)=7.86, p=.006]$, item $3[F(1,134)=8.26, p=.005]$, and item $5[F(1,133)=$ $12.30, p<.001]$ with scores increasing significantly from the initial screening to 3 month follow-up For Item 4, there was a significant interaction between condition and time $[F(1,134)=8.95, p=.003]$. Dependent t-tests were used to analyze the differences 
between groups across measurement times. For the experimental group, the large class screening $(M=4.62, S D=1.32)$ to 3 month follow up $(M=5.52, S D=1.03)$ comparison was significant $(\mathrm{t}(81)=-6.91, p<.001)$. However, for the control group, the large class screening $(M=4.76, S D=1.50)$ to the 3 month follow up $(M=5.02, S D=1.19)$ comparison was not significant $(\mathrm{t}(53)=-1.48, p=.15)$. Finally, there were no significant main effects or interactions for items 1 and 6. See Figure 1 for mean comparisons on PMHCCQ items over time collapsed across groups.

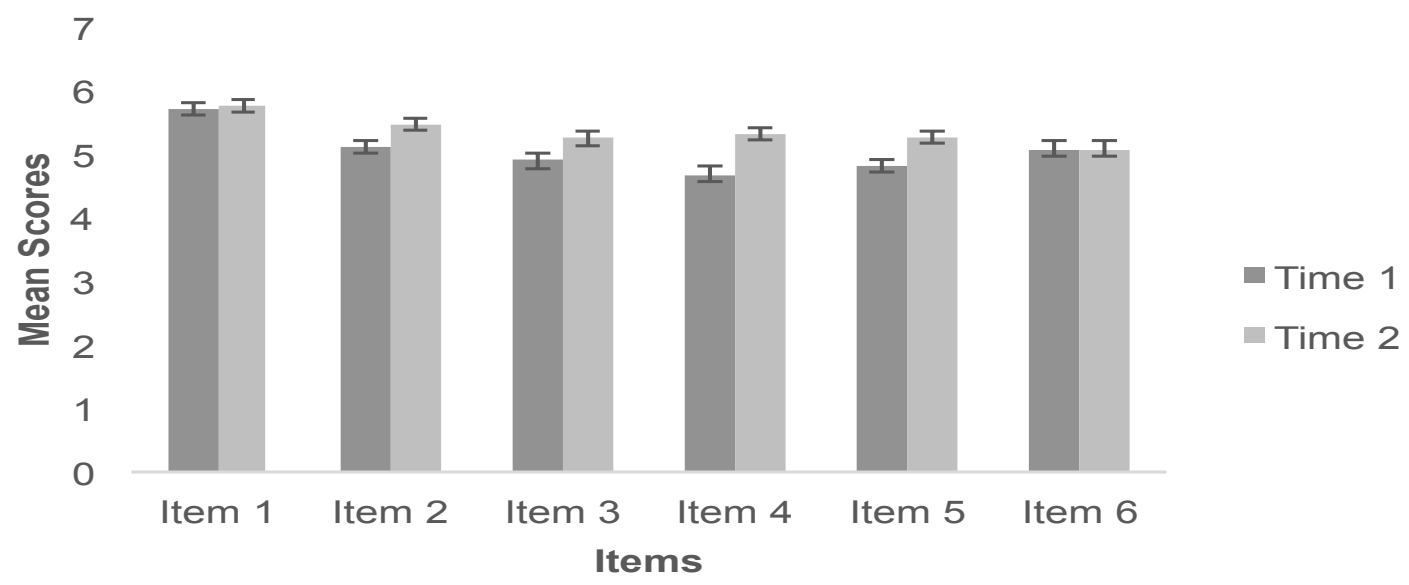

Figure 1. Mean scores on individual items of the Perceptions of Mental Health Care on Campus Questionnaire with error bars displaying the standard error 


\section{COMMENT}

Of the students who participated in screening phase of the experiment, $64 \%(n=$ 158) obtained scores considered to be "at risk" on at least one subscale of a mental health screening tool. These findings indicate that the majority of students in a large introductory psychology course reported distress at a significant level. Developers of the CCAPS-62 provide two "cut-off" scores (low-cut score and high-cut score) and indicated that students in treatment at a university counseling center typically fall above the lowcut score. ${ }^{14}$ For the purposes of the current study, we chose to identify students based only on the high-cut score, suggesting that an even higher percentage of students would have been identified using the low-cut score. Although many of those students were determined to be at minimal/low risk during the follow-up stage, $33.3 \%(n=21)$ of the students who chose to follow-up were determined to be in need to counseling services for concerns more significant than typical adjustment issues, consistent with our initial hypothesis. However, considering only $39.9 \%$ of participants who elevated on one or more scales actually chose to follow-up, it is likely that more students were in need of a referral.

These findings suggest that a large number of students are struggling to some degree. These data support the need for more widespread mental health screening on our campus in order to identify students who may not self-identify in typical mental health screening formats and may not be aware that they could benefit from receiving mental health treatment. 
Although 158 individuals were invited to participate in the follow-up phase, less than half of them (39.9\%) participated. There were a number of individuals who formally declined the invitation, and there were $38.6 \%$ who either never responded or expressed interest in participating, but never followed through. In the future, attempts to specifically target these individuals and increase their likelihood of engaging in the follow-up phase would be important. One potential obstacle for completing the follow-up could have been scheduling issues. In order to try and share the caseload, graduate clinicians were assigned a specific number of students. It is possible that students may not have followed up due to scheduling conflicts with their assigned graduate clinician. Although we did express that the students could still have the opportunity to meet with someone in the case of scheduling conflicts, that additional obstacle could have been enough to prevent participation. In the future, it could be beneficial to allow students the opportunity to sign up for any available timeslot and then allow graduate clinicians to pick up case files once scheduling is completed. One other potential explanation for the relatively low individual follow-up rate could be that the participants who chose not to follow-up did not need any additional research credit for their course and therefore lacked motivation to participate. In the future, increasing motivation to participate through other incentives might be helpful.

The PMHCCQ also provided interesting data regarding changes in student perceptions over time. Between the initial screening phase and 3-month follow-up, participants at the 3-month follow-up had stronger beliefs that the university should be more involved in promoting student mental health. At the 3-month follow-up they also reported feeling more comfortable discussing student mental health on campus, agreed 
more strongly that the university is invested in their mental health, and that mental health is a priority on our campus. It is interesting that students felt more strongly, at the end of participating in the research, that the university still should be involved, even though they agree that the university is already placing mental health as a priority. This question was worded as a "negative" belief, so it was hypothesized that individuals would agree with this statement less after participating. It appears the students generally agreed that the university cares about mental health, but they also indicated a belief that even more work could be done to continue promoting mental health on campus. Additionally, it is interesting that participants in the control group did not respond to these questions differently than participants in the experimental group, which was contrary to our second hypothesis. Perceptions about mental health priorities on campus generally improved in both groups over time. One possible explanation of this finding is that participants in the control group were exposed to the same informed consent as participants in the experimental group so that the control participants knew that a large-scale mental health screening was being conducted on campus despite their lack of participation in the screening individually. That knowledge could have led to improved perceptions of mental health priorities on campus. It is also possible that students (mostly first-semester freshman) simply became more aware of mental health priorities on campus over time and that the current intervention was not responsible (or not solely responsible) for the improvement in perceptions.

\section{Limitations}

Although prior research has focused on prevalence rates with regard to clinical 
diagnoses, the CCAPS-62 is not meant to be a diagnostic indicator. Therefore, the current percentage of students who scored in an "at risk" range on any of the CCAPS-62 subscales should not be compared directly to previous research on prevalence of mental health diagnoses on college campuses.

Regarding the PMHCCQ, there was significant participant attrition due to data being collected months apart. It is possible that students who felt more positively about the mental health priorities on campus were more likely to respond to the follow-up PMHCCQ questions.

The generalizability of our sample is also a limitation. A total of $86.9 \%$ of our sample self-identified as "White" and the mean participant age was 19-years-old which is not representative of a diverse college population. However, these demographics are similar to the normative sample of the CCAPS- 62 with $71.2 \%$ of participants selfidentifying as "White" and a modal age of 19-years-old. ${ }^{14}$

While the current study evaluated a method of universal screening that reduced resources (both human resources and space resources), it is important to note that the resources required to complete the screening in only one section of the five sections of Introductory Psychology were significant. The planning phase of the study required extensive consultation with various campus entities including the Institutional Review Board, legal counsel, counseling center, and departmental/college administration. Although by utilizing graduate student clinicians we were able to redirect the pressure away from the counseling center staff, there were still many personnel needed to make this possible including graduate student clinicians, clinical psychology faculty members, and undergraduate research assistants. 


\section{Conclusions}

This current study demonstrates that universal screening can be conducted successfully with the use of graduate clinicians and online interviewing tools. Through this study, a large number of individuals were identified and referred for mental health services. Future work should focus on trying to improve the follow-up rate among students who score in an "at risk" range on a self-report screening measure.

Although universal screening does require significant resources, using graduate student clinicians can help reduce the demands on the university and campus counseling centers. In addition, the graduate students themselves also benefit by gaining clinical experience. For institutions that do not have graduate programs, partnering with an institution that does have graduate training might be possible. Additionally, the use of online platforms to conduct confidential individual follow-up interviews can further reduce the resource demands for institutions. Although not every student may have access to a web camera or smartphone, the number of students who would require an inperson follow-up appear to be minimal compared to those who can meet through an electronic medium. Overall, the current study suggests that universal screening is possible to implement using creative methods to reduce resource demands, however the resources still used are significant. 


\section{REFERENCES}

1. Reetz DR, Bershad C, LeViness P, Whitlock M. The association for universities and college counseling center directors annual survey. Association for University and College Counseling Center Directors. 2017; 1-118. https://www.aucccd. org/assets/documents /aucccd\%202016\%20monograph\%20-\%20public.pdf. Accessed March 16, 2018.

2. Mistler BJ, Reetz DR, Krylowicz B, Barr V. The association for universities and college counseling center directors annual survey. Association for University and College Counseling Center Directors. 2013;1-188. http://files.cmcglobal.com/Monograp h_2012_AUCCCD_Public.pdf. Accessed March 29, 2018.

3. Lipson S, Gaddis S, Heinze J, Beck K, Eisenberg D. Variations in Student Mental Health and Treatment Utilization Across US Colleges and Universities. J Am Coll Health. 2015;63(6):388-396. doi:10.1080/07448481.2015.1040411

4. Eisenberg D, Hunt J, Speer, N, Zivin K. Mental health service utilization among college students in the United States. J Nerv Ment Dis. 2011;199(5):301-308. doi:10.1097/NMD.0b013e3182175123

5. Locke B, Wallace D, Brunner J. Emerging Issues and Models in College Mental Health. New Directions for Student Services. 2016;2016(156):19-30. doi.org/10.1002/ss.20188

6. Soo Jeong Y, Nhi-Ha T, Yeung A, et al. Using online social media, Facebook, in screening for major depressive disorder among college students. International Journal Of Clinical Health \& Psychology. 2013;13(1):74-80. doi:10.1016/s1697-2600(13)700103

7. Dowdy E, Furlong M, Murdock J, et al. Enhancing school-based mental health services with a preventive and promotive approach to universal screening for complete mental health. Journal Of Educational \& Psychological Consultation. 2015;25(2/3):178197. doi:10.1080/10474412.2014.929951

8. Furr S. Training graduate students in college counseling centers: do the benefits outweigh the costs?. J Coll Couns. 1999;2(1):42. doi:10.1002/j.2161-1882.1999.tb00141 . $\mathrm{x}$

9. Ruiz Rodríguez J, Bados López A, Escolano AF, et al. Peer counselling versus role-playing: two training methods of therapeutic skills in clinical psychology.

Psicothema. 2018;30(1):21-26. doi:10.7334/psicothema2016.286 
10. Perle J, Burt J, Higgins W. Psychologist and physician interest in telehealth training and referral for mental health services: an exploratory study. J Technol Hum Serv. 2014;32(3):158-185. doi:10.1080/15228835.2014.894488

11. Fenichel M, Suler J, Walker-Schmucker W, et al. Myths and Realities of Online Clinical Work. Cyberpsychol Behav. 2002;5(5):481-497. doi:10.1089/109493102761022904

12. Andersson G, Nordgren L, Buhrman M, Carlbring P. Psychological treatments for depression delivered via the internet and supported by a clinician: an update. Revista De Psicopatologia Y Psicologia Clinica. December 2014;19(3):217-225. doi: 10.5944/rppc.vol.19.num.3.2014.13903

13. Locke B, Buzolitz J, Hayes J, et al. Development of the counseling center assessment of psychological symptoms-62 (CCAPS-62). J Couns Psychol. 2011;58(1):97-109. doi:10.1037/a0021282

14. Center for Collegiate Mental Health. CCAPS User Manual. University Park, PA: The Pennsylvania State University; 2015. 


\section{APPENDICES}

\section{Appendix A. Perception of Mental Health Care on Campus Questionnaire (PMHCCQ)}

\begin{tabular}{|l|c|c|c|c|c|c|c||}
\hline & $\begin{array}{l}\text { Strongly } \\
\text { Disagree }\end{array}$ & Disagree & $\begin{array}{l}\text { Somewhat } \\
\text { Disagree }\end{array}$ & Neutral & $\begin{array}{c}\text { Somewhat } \\
\text { Agree }\end{array}$ & $\begin{array}{c}\text { Agree } \\
\text { Strongly } \\
\text { Agree }\end{array}$ \\
\hline $\begin{array}{l}\text { 1. I believe that MSU } \\
\text { cares about student } \\
\text { mental health. }\end{array}$ & 1 & 2 & 3 & 4 & 5 & 6 & 7 \\
\hline $\begin{array}{l}\text { 2. I think that MSU } \\
\text { should be more actively } \\
\text { involved in promoting } \\
\text { student mental health. }\end{array}$ & 1 & 2 & 3 & 4 & 5 & 6 & 7 \\
\hline $\begin{array}{l}\text { 3. I feel comfortable } \\
\text { discussing issues about } \\
\text { mental health on campus. }\end{array}$ & 1 & 2 & 3 & 4 & 5 & 6 & 7 \\
\hline $\begin{array}{l}\text { 4. MSU is invested in my } \\
\text { mental health. }\end{array}$ & 1 & 2 & 3 & 4 & 5 & 6 & 7 \\
\hline $\begin{array}{l}\text { 5. Mental health is a } \\
\text { priority on MSU's } \\
\text { campus. }\end{array}$ & 1 & 2 & 3 & 4 & 5 & 6 & 7 \\
\hline $\begin{array}{l}\text { 6. It is easy to go } \\
\text { unnoticed with a mental } \\
\text { health issue on MSU's } \\
\text { campus. }\end{array}$ & 1 & 2 & 3 & 4 & 5 & 6 & 7 \\
\hline
\end{tabular}




\section{Appendix B. Human Subjects IRB Approval}

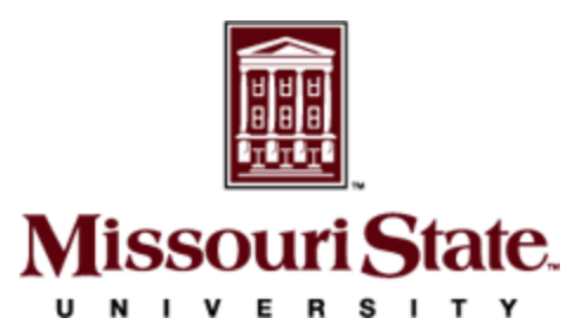

To:

Brooke Whisenhunt

Psychology

RE: Notice of IRB Approval

Submission Type: Initial

Study \#: IRB-FY2018-196

Study Title: Making Mental Health a Priority on College Campuses: Implementing Large Scale Screening and Follow-up in a High Enrollment Gateway Course

Decision: Approved

Approval Date: Oct 20, 2017

Expiration Date: Oct 18, 2018

This submission has been approved by the Missouri State University Institutional Review Board (IRB) for the period indicated. 


\section{Appendix C. Follow-Up Phase Risk Level Criteria}

- Minimal - No Treatment Recommended

- Low Distress

\begin{tabular}{|l|l|}
\hline & No suicidal ideation \\
\hline & No more than slight impairment in functioning (ex. Procrastinating) \\
\hline & Typical adjustment issues \\
\hline
\end{tabular}

- Moderate Distress

\begin{tabular}{|l|l|}
\hline & Passive suicidal ideation with no plan \\
\hline & Mildly depressed or anxious mood \\
\hline & Mild insomnia or concentration problems \\
\hline $\begin{array}{l}\text { Occasionally missing class due to emotional distress, occasional } \\
\text { interpersonal conflict }\end{array}$ \\
\hline
\end{tabular}

- High Distress

\begin{tabular}{|l|l|}
\hline & Frequent suicidal ideation with or without vague plan but no serious intent \\
\hline & Frequently missing class, frequent interpersonal conflict \\
\hline & Persistent depressed mood, frequent panic attacks, significant insomnia \\
\hline Impaired academic performance, socially isolated/withdrawn \\
\hline $\begin{array}{l}\text { Risky behaviors such as binge drinking, drug use, and unprotected sexual } \\
\text { behavior }\end{array}$ \\
\hline
\end{tabular}

- Crisis Situation

\begin{tabular}{|l|l|}
\hline & Suicidal ideation with plan and possible intent \\
\hline & Needs immediate assistance to regain baseline functioning \\
\hline & Acute anxiety, persistent/severe depressed mood \\
\hline $\begin{array}{l}\text { May occur in connection to a catastrophic life event (ex. death or serious } \\
\text { illness in a family member) }\end{array}$ \\
\hline & Able to participate in safety planning \\
\hline
\end{tabular}

- Emergency Situation with clear and present danger for possible harm to self/others (intervention within 24 hours)

\begin{tabular}{|l|l|}
\hline & Clear risk for harm to self or others with plan and intent \\
\hline $\begin{array}{l}\text { Acute depression with possible psychotic features, manic episode with } \\
\text { impaired reality testing }\end{array}$ \\
\hline & Recent suicide attempt \\
\hline & Disorganized though and behavior \\
\hline & Not able to participate in safety planning \\
\hline
\end{tabular}

*Utilized due to triage protocol and levels provided by the campus counseling center 